\title{
Nitrone-Mediated Radical Coupling of Polymers Derived from Reverse Iodine-Transfer Polymerization
}

\author{
Kayte Ranieri, Joke Vandenbergh, Christopher Barner-Kowollik, ${ }^{*}$ \\ Thomas Junkers*
}

The current study describes the synthesis of iodine-end-capped polystyrene (PS) and poly(methyl methacrylate) (PMMA) precursors using reverse iodine-transfer polymerization, which, in a second step, are used in nitrone-mediated radical coupling (NMRC) reactions. Initially, the reverse iodine polymerization of both monomers is studied and optimized in order to obtain iodine-end-capped materials with controlled molecular weights and low dispersities. Subsequently, NMRC of both PS and PMMA precursors is carried out in the presence of $\mathrm{CuCl}$ as a halide-exchange agent. Coupling efficiencies of $x_{\mathrm{c}}=0.754$ for PS-I and 0.84 for PMMA-I are observed; however, the addition of 10 equivalents of styrene is required to promote the coupling in the case of methacrylate. The presence of the desired alkoxyamine functionality in mid-chain position of the products is evidenced via quenching experiments.

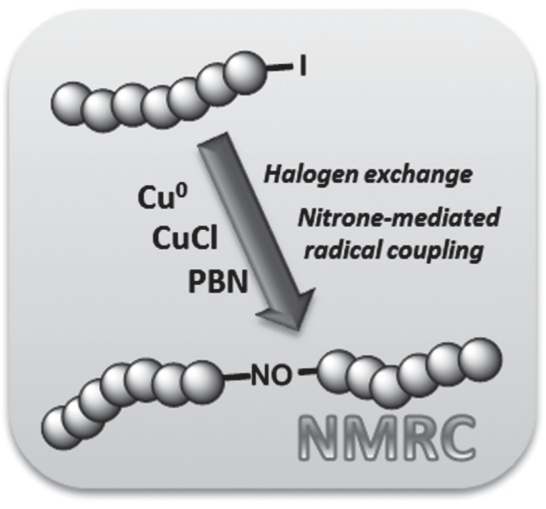

\section{Introduction}

Since the advent of the controlled radical polymerization (CRP) techniques, a wide range of methods has been introduced to synthesize polymers with various interesting architectures. Macromolecular architectures such as block copolymers, graft copolymers, or telechelic polymers are widely accessible in a facile manner, ${ }^{[1-4]}$ with atom

K. Ranieri, Dr. J. Vandenbergh, Prof. T. Junkers

Polymer Reaction Design (PRD), Institute for Materials

Research (imo-imomec), Hasselt University, Agoralaan

Building D, 3590, Diepenbeek, Belgium

E-mail: thomas.junkers@uhasselt.be

Prof. C. Barner-Kowollik

Preparative Macromolecular Chemistry, Institut für Technische Chemie und Polymerchemie, Karlsruhe Institute of Technology

(KIT), Engesserstr. 18, 76128, Karlsruhe, Germany

E-mail: christopher.barner-kowollik@kit.edu

Prof. C. Barner-Kowollik

Institut für Biologische Grenzflächen, Karlsruhe Institute of

Technology (KIT), Hermann-von-Helmholtz-Platz 1, 76344,

Eggenstein-Leopoldshafen, Germany transfer radical polymerization (ATRP), ${ }^{[5-8]}$ nitroxidemediated radical polymerization (NMP), ${ }^{[9,10]}$ and reversible addition-fragmentation polymerization (RAFT) ${ }^{[11,12]}$ being the most prominent techniques. One of the oldest controlling protocols is iodine transfer polymerization (ITP). ${ }^{[13-18]}$ More recently, reverse iodine-transfer polymerization (RITP) has been developed as an alternative to produce iodine-end-capped polymers. ${ }^{[19-28]}$ This method has advantages over ITP, as there is no need for iodinated transfer agents but rather free iodine $\left(\mathrm{I}_{2}\right)$ alongside a conventional initiator is employed. RITP is thereby based on the in situ synthesis of the iodinated transfer agent, (see Scheme 1). During an initial inhibition period, radicals A. react with iodine to preferentially form A-I or to propagate with a few monomer units before reacting with iodine to provide short telomers, $\mathbf{A}-\mathbf{M n}-\mathbf{I}$. A second equilibrium then comes into play where the radicals follow a controlled polymerization governed by degenerative chain transfer.

An alternative technique well suited for the synthesis of complex architectures is nitrone-mediated radical coupling (NMRC) (see Scheme 2), which has been recently 


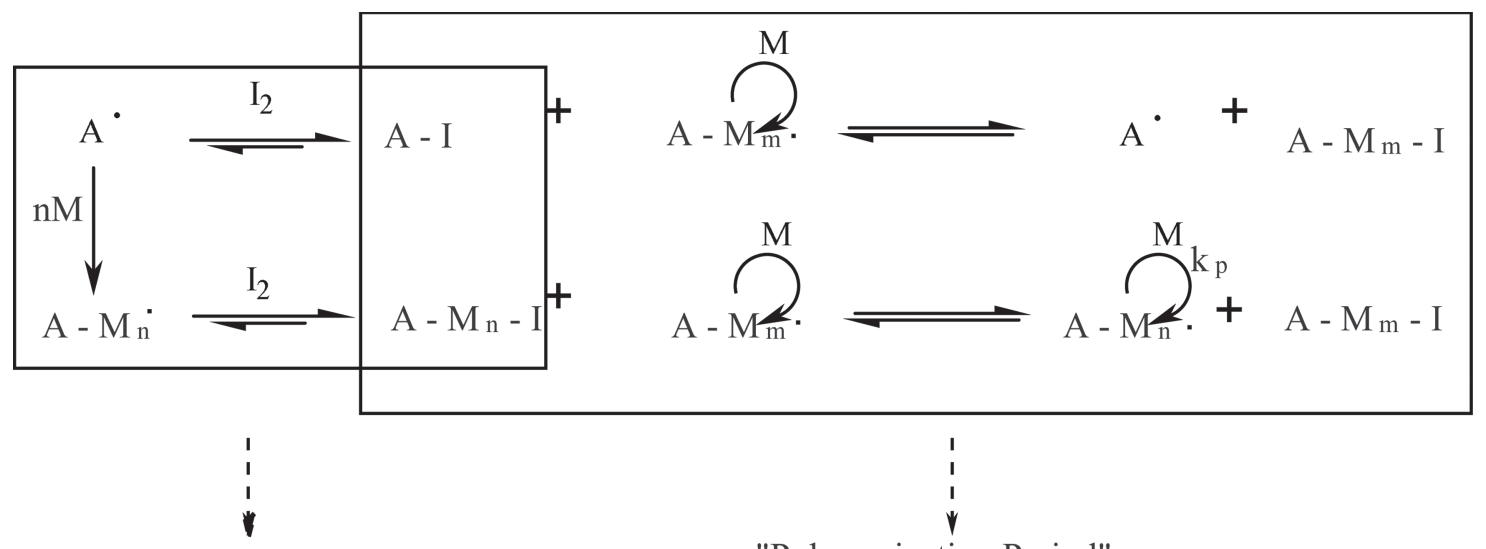

in situ formation

"Polymerization Period"

of the transfer agents

A - $M_{n}-I(n>=0)$

"Inhibition Period"

Scheme 1. Simplified reaction scheme for the mechanism of reverse iodine-transfer polymerization (RITP).

identified as an efficient method for radical-radical coupling reactions. ${ }^{[29-36]}$ It has originated from the development of enhanced spin capturing polymerization (ESCP) in which nitrone spin traps act as a chain-regulating control agent. ${ }^{[37-42]}$ NMRC has been added to the synthetic polymer toolbox as an innovative means for constructing macromolecules with exact site-specific functionalities in a mid-chain position of chains rather than at its end groups. Upon the formation of radicals (generated from a macromonomer with at least one halide functional

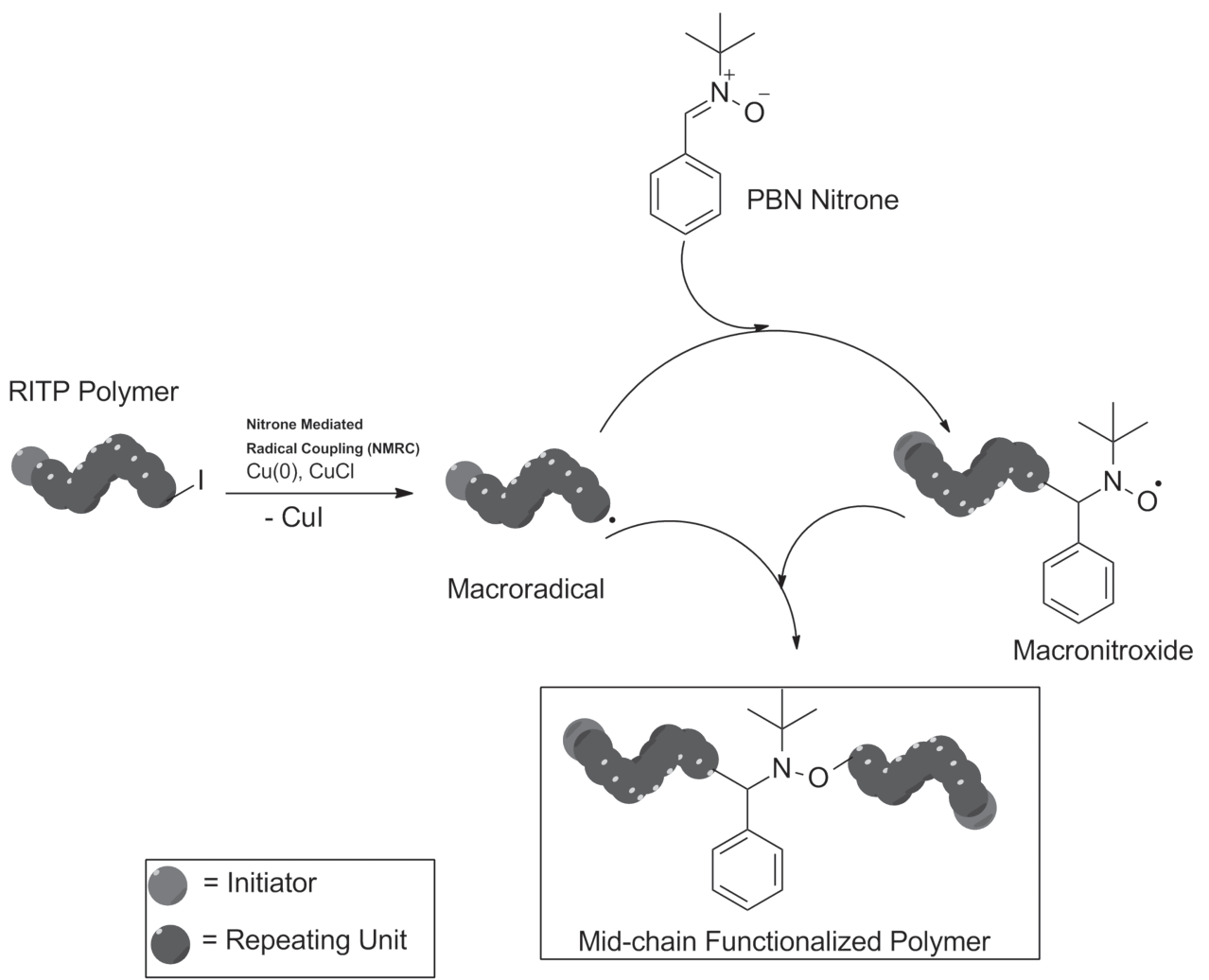

Scheme 2. General reaction mechanism for nitrone-mediated radical coupling (NMRC). 
chain end activated with a suitable copper/ligand catalyst system), macronitroxides are formed in high yields from the rapid addition of macroradicals to the nitrone. These macronitroxides further react with a second radical species forming an alkoxyamine, which will contain the functionality precisely mid-chain centered. To successfully employ NMRC, the nitrones must be able to react efficiently with macroradicals to form macronitroxides. These mid-chain functional alkoxyamine polymers can be further used to perform post-polymerization reactions (i.e., the chains can be reactivated using NMP) employing the NMRC product as a macroinitiator, thus allowing for the synthesis of ABA-type triblock copolymers. ${ }^{[32]}$ A second possibility is to use the nitrone and thus the residual alkoxyamine as a functional carrier allowing for the introduction of specific functionalities such as alkynes or azides at a controlled position in the middle of the chain. ${ }^{[33]}$

Previously, two model polymer systems of polystyrene (PS) and poly(isobornyl acrylate), prepared via ATRP, have been successfully subjected to NMRC reactions. These reactions yielded highly functionalized (>90\%) polymers with precisely mid-chain centered alkoxyamine functions. Starting from cobalt-functional materials, poly(vinyl acetate) and poly(acrylonitrile) have been coupled successfully, too. ${ }^{[35]}$ For poly(methyl methacrylate) (PMMA) until now, only ESCP (copolymerization with low amounts of styrene) has been achieved, yet no successful NMRC was reported thus far. ${ }^{[14,43-45]}$ PMMA is challenging to subject to radical coupling reactions since its macroradicals are prone to disproportionate. Furthermore, nitroxides also show a distinct propensity to disproportionate with methyl methacrylate (MMA) radicals, thus also complicating classical NMP of MMA. In NMRC, an additional obstacle is the relatively low addition rate of radicals to the nitrone. In ESCP, this low addition rate was overcome by adding small amounts of styrene to the polymerization mixture, thus ensuring that macroradicals with a styrene terminus react with the nitrone, followed by coupling with surrounding radical species.

In the present work, we describe the synthesis of RITP PMMA and PS precursors where emphasis is placed on high-end-group fidelities to later allow for efficient chain coupling. Using these precursors, the successful application of NMRC is subsequently demonstrated. It should be noted that also analogue reactions were performed on RITP of butyl acrylate and NMRC of the residual poly(butyl acrylate) polymers. Due to inherent difficulties in the RITP of acrylates, these reactions were, however, not successful and are thus only described in the Supporting Information. With these examples, spin-trap-assisted radical coupling is for the first time exemplified for an iodine-terminal polymer, thus broadening the scope of this type of reactions significantly. Additionally, the use of an halogen exchange reaction (via $\mathrm{CuCl}$ ) is demonstrated, which - to the best of our knowledge-has not been applied to radical coupling reactions as well. Last but not least, also the use of styrene as a reactivity moderator is introduced in order to avoid the above-described typical disproportionation and slow spin trap addition rates usually associated with MMA macroradicals.

\section{Experimental Section}

\subsection{Materials}

2,2'-Azobis(isobutyronitrile) (AIBN) was recrystallized twice from methanol. MMA (99\%; Aldrich), styrene (Sty) (99\%; Aldrich), and $n$-butyl acrylate (BuA) (99\%; Aldrich) were de-inhibited by percolating over a column of basic alumina. Copper (I) bromide ( $\mathrm{CuBr}$ ) (98\%; Acros) was washed with glacial acetic acid overnight to remove any soluble-oxidized species before being filtered, rinsed with ethanol, and dried. Iodine $\left(\mathrm{I}_{2}\right)$ (99.8\%, Aldrich), toluene (99\%; Aldrich SDS), $N, N, N^{\prime}, N^{\prime \prime}, N^{\prime \prime}$-pentamethyldiethylenetriamine (PMDETA) (99\%; Acros), 1,1,4,7,10,10-Hexamethyltriethylenetetramine (HMTETA) (97\%; Aldrich), copper (I) chloride (CuCl) $(99 \%$; Aldrich), copper powder <63 $\mathrm{m}$ ( $\mathrm{Cu}(0))$ (99.7\%; Merck), tributyltin hydride (TBTH) (97\%; Aldrich), pentane (99\%, VWR), and methanol (99\%, VWR) were used as received.

\subsection{Characterization}

Analysis of the molecular weight distribution of the polymer samples was performed on an TOSOH EcoSEC HLC-8320GPC instrument, comprising an autosampler, a PSS SDV 5 microguard $(5 \mathrm{~cm})$, followed by three PSS SDV 5 linear XL $(30 \mathrm{~cm})$ columns thermostated at $40{ }^{\circ} \mathrm{C}$ (column molecular weight range: $1 \times 10^{2}-1 \times 10^{6} \mathrm{~g} \mathrm{~mol}^{-1}$ ). THF was used as the eluent with a

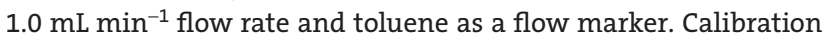
was performed with PS standards from PSS Laboratories in the range of 470-7.5 $\times 10^{6} \mathrm{~g} \mathrm{~mol}^{-1}$. The following Mark-Houwink coefficients were applied: PS $\left(K=14.10 \times 10^{-5} \mathrm{dL} \mathrm{g}^{-1}, \alpha=0.700\right)$, ${ }^{[46]}$ poly(butyl acrylate) $\left(K=12.20 \times 10^{-5} \mathrm{dL} \mathrm{g}^{-1}, \alpha=0.700\right){ }_{,}^{[47]}$ and PMMA $\left(K=12.98 \times 10^{-5} \mathrm{dL} \mathrm{g}^{-1}, \alpha=0.688\right) .{ }^{[48]}$ NMR spectra were recorded with two NMR spectrometers (300 and $400 \mathrm{MHz}$, 64 scans, $12 \mathrm{~s}$ relaxation) from Oxford Instruments Ltd. using a Varian probe head (9 mm-4-nucleus AutoSWPFG) in $\mathrm{CDCl}_{3}$.

Electrospray ionization mass spectrometry (ESI-MS) was performed using an LCO Fleet mass spectrometer (ThermoFischer Scientific) equipped with an atmospheric pressure ionization source operating in the nebulizer-assisted electrospray mode. The instrument was calibrated in the $m / z$ range $220-2000$ using a standard solution containing caffeine, MRFA, and Ultramark 1621. A constant spray voltage of $5 \mathrm{kV}$ was used, and nitrogen at a dimensionless auxiliary gas flow rate of 3 and a dimensionless sheath gas flow rate of 3 was applied. The capillary voltage, the tube lens offset voltage, and the capillary temperature were set to $25 \mathrm{~V}, 120 \mathrm{~V}$, and $275^{\circ} \mathrm{C}$, respectively. A $250 \mu \mathrm{L}$ aliquot of a polymer solution with concentration of $20 \mu \mathrm{g} \mathrm{mL}^{-1}$ was injected. A mixture of dichloromethane (DCM) and methanol (DCM$\mathrm{MeOH}=1: 3$ ), all HPLC grade, was used as a solvent.

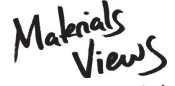

www.MaterialsViews.com
Macromol. Chem. Phys. 2014, 215, 1991-2000

(c) 2014 WILEY-VCH Verlag GmbH \& Co. KGaA, Weinheim 


\subsection{Synthesis}

\subsubsection{Preparation of $\alpha$-Phenyl-N-tert-butylnitrone (PBN) (1)}

The preparation of PBN was adapted from ref. ${ }^{[40]}$ The material identity, purity, and quality were confirmed by proton and carbon NMR. ${ }^{1} \mathrm{H}$ NMR $\left(300 \mathrm{MHz}, \mathrm{CDCl}_{3}, 25{ }^{\circ} \mathrm{C}, \delta\right): 8.31-8.28(\mathrm{~m}$, $\left.2 \mathrm{H}, 2 \mathrm{H}_{\text {aromatic }}\right), 7.55(\mathrm{~s}, 1 \mathrm{H},-\mathrm{CH}=\mathrm{N}), 7.43-7.41\left(\mathrm{~m}, 2 \mathrm{H}, 2 \mathrm{H}_{\text {aromatic }}\right)$, $1.63\left(\mathrm{~s}, 9 \mathrm{H},-\mathrm{C}\left(\mathrm{CH}_{3}\right)_{3}\right) .{ }^{13} \mathrm{C} \mathrm{NMR}\left(300 \mathrm{MHz}, \mathrm{CDCl}_{3}, 25{ }^{\circ} \mathrm{C}, \delta\right): 28.3$, 70.5 (N-tert-butyl), $131.0(\mathrm{CH}=\mathrm{N}), 130.0,129.7,128.7,128.3(\mathrm{Ph})$.

\subsubsection{Synthesis of P-I Polymers by RITP}

The synthesis of PMMA-I (2) was performed with a ratio of $[\mathrm{MMA}] /[\mathrm{AIBN}] /\left[\mathrm{I}_{2}\right]=240 / 1.7 / 1$ and $M_{\mathrm{n} \text {,targeted }}=12100 \mathrm{~g} \mathrm{~mol}^{-1}$. MMA (9.98 g, $\left.1 \times 10^{-1} \mathrm{~mol}\right)$, AIBN $\left(0.121 \mathrm{~g}, 7.3 \times 10^{-4} \mathrm{~mol}\right)$, iodine $\left(0.11 \mathrm{~g}, 4.2 \times 10^{-4} \mathrm{~mol}\right)$, and toluene $(10.0 \mathrm{~g})$ were introduced into a Schlenk flask and were freed from oxygen via three consecutive freeze-pump-thawed cycles. The flask was then introduced into a nitrogen environment (glovebox) and divided equally into 11 portions (by mass) in brown glass vials equipped with stirrer bars. Using a thermostated heating block at $75{ }^{\circ} \mathrm{C}$, the vials were heated and removed after predetermined times. The polymerization was stopped by first allowing the reaction mixture to return to ambient temperature, where after a small portion of hydroquinone: $\mathrm{MeOH}$ was added. The reaction mixtures were subsequently transferred into a preweighed aluminum pan and conversion was determined gravimetrically. The polymer was stored in the dark until dried. Molecular weights were determined via size exclusion chromotography with tetrahydrofuran (THF-SEC) as an eluent.

Polymerization of styrene (Sty) to afford PS-I (3) was performed in the same manner as above except with $M_{\mathrm{n} \text {,targeted }}=9600 \mathrm{~g} \mathrm{~mol}^{-1}$ and $\left[\right.$ Sty] $/[$ AIBN] $] /\left[\mathrm{I}_{2}\right]=180 / 1.8 / 1$.

\subsubsection{Synthesis and Characterization of a Macro-transfer} Agent PS-I with $M_{n \text {,targeted }}=2700 \mathrm{~g} \mathrm{~mol}^{-1}$ ([Sty $] /[\mathrm{AIBN}] /\left[\mathrm{I}_{2}\right]=$ 48/1.7/1) (4)

Sty $\left(6.00 \mathrm{~g}, 5.7 \times 10^{-2} \mathrm{~mol}\right)$, AIBN $\left(0.335 \mathrm{~g}, 1.2 \times 10^{-3} \mathrm{~mol}\right)$, iodine $\left(0.304 \mathrm{~g}, 1.2 \times 10^{-3} \mathrm{~mol}\right)$, and toluene $(6.0 \mathrm{~g})$ were introduced into a $50 \mathrm{~mL}$ round-bottom flask. After degassing the solution for $10 \mathrm{~min}$ at $0{ }^{\circ} \mathrm{C}$ with nitrogen, the flask was introduced to an oil bath at $70{ }^{\circ} \mathrm{C}$ with magnetic stirring for $24 \mathrm{~h}$. The polymerization was conducted in the dark. After the reaction, the polymerization was stopped and allowed to return to ambient temperature after which it was directly precipitated into cold methanol, filtered, and dried under vacuum in the dark. The polymer was stored in the dark at $3{ }^{\circ} \mathrm{C}$. Molecular weights were determined by both SEC and ${ }^{1} \mathrm{H}$ NMR. Polymerization time $=24 \mathrm{~h}$, styrene conversion $=$ $58 \%, M_{\mathrm{n} \text {,theoretical }}=1640 \mathrm{~g} \mathrm{~mol}^{-1}, M_{\mathrm{n}, \mathrm{SEC}}=1830 \mathrm{~g} \mathrm{~mol}^{-1}, \boxplus=1.26$, $D P_{\mathrm{n}, \mathrm{SEC}}=17.6$, and $M_{\mathrm{n}, \mathrm{H} \mathrm{NMR}}=1800 \mathrm{~g} \mathrm{~mol}^{-1}$.

\subsubsection{Synthesis and Characterization of a Macro-transfer} Agent PMMA-I with $M_{n \text {,targeted }}=3200 \mathrm{~g} \mathrm{~mol}^{-1}([\mathrm{MMA}] /$ $\left.[\mathrm{AIBN}] /\left[\mathrm{I}_{2}\right]=60 / 1.7 / 1\right)(5)$

MMA (20.00 g, $\left.2.0 \times 10^{-1} \mathrm{~mol}\right)$, AIBN (0.93 g, $\left.5.6 \times 10^{-3} \mathrm{~mol}\right)$, iodine $\left(0.84 \mathrm{~g}, 3.3 \times 10^{-3} \mathrm{~mol}\right)$, and toluene $(20.00 \mathrm{~g})$ were introduced into a three-necked flask covered in aluminum foil and equipped with a condenser. The solution was degassed with nitrogen for $10 \mathrm{~min}$ at $0{ }^{\circ} \mathrm{C}$ and subsequently introduced into an oil bath at $80{ }^{\circ} \mathrm{C}$ under magnetic stirring and constant nitrogen flow. The reaction was performed three separate occasions for $6,6.15$, and $6.45 \mathrm{~h}$, respectively. The polymer was allowed to reach room temperature and was directly precipitated into cold methanol, filtered, and dried under vacuum in the dark. The polymer was stored in the dark at $3{ }^{\circ} \mathrm{C}$ and the molecular weights were determined by SEC and ${ }^{1} \mathrm{H}$ NMR. The sample from $6 \mathrm{~h}$ was further characterized by ESI-MS.

\subsubsection{Typical Procedure for the NMRC with PBN}

RITP PMMA (5) (250 mg, 1 eq.), PBN (5 eq.), Cu(0) (5 eq.), and $\mathrm{Cu}(\mathrm{I}) \mathrm{Cl}$ ( 1 eq.) were introduced to a glovebox in a brown glass vial with a stirring bar. Styrene (10 eq.), which was subjected to three consecutive freeze-pump-thaw cycles, was then added. The mixture was further dissolved in $1.0 \mathrm{~mL}$ toluene in a brown glass vial, to make a 1 molar solution of PMMA-I. Degassed PMDETA (10 eq.) was transferred into the vial. The reaction mixture was heated at $60{ }^{\circ} \mathrm{C}$ in a thermostated heating block for $20 \mathrm{~h}$. The resulting conjugated PMMA (6) was purified by passing over a column of basic alumina to remove copper complexes. The copper-free polymer solution was subsequently concentrated and precipitated in cold methanol as a yellow powder before being analyzed by THF-SEC. The coupling efficiency, $x_{\mathrm{c}}, M_{\mathrm{n}}=0.84$ was calculated from the molecular weight of the polymeric precursor $M_{\mathrm{n}, 0}$ and of the coupling product $M_{\mathrm{n}}$ using Equation 1:[49]

$$
\chi_{\mathrm{c}}=2 \cdot\left(1-\frac{M_{\mathrm{n}, \mathrm{o}}}{M_{\mathrm{n}}}\right)
$$

PS-I (4) coupling reactions were performed in a similar fashion using HMTETA as a ligand and without the addition of styrene (7).

\subsubsection{Typical Procedure for Polymer Quenching}

In a $25 \mathrm{~mL}$ round-bottom flask either coupled PMMA (6) or coupled PS (7) $(10 \mu \mathrm{mol})$ was dissolved in $538 \mu \mathrm{L}$ DMF before adding TBTH ( $538 \mu \mathrm{L}, 2 \mathrm{mmol}$ ) such that the ratio of polymer to quencher is $1: 200$. The solution was subsequently heated at $125^{\circ} \mathrm{C}$ overnight. The polymer was then allowed to return to ambient temperature; where after it was filtered over a column of basic alumina using THF as an eluent. The solvent was then removed by evaporation overnight before the quenched polymer was analyzed by THF-SEC.

\section{Results and Discussion}

\subsection{Synthesis of P-I Polymers via RITP}

Previously, the RITP of PMMA-I has been studied in detail at 70 and $80{ }^{\circ} \mathrm{C}$ by Boutevin and co-workers. ${ }^{[20]}$ It was determined that the ratio of $[\mathrm{AIBN}] /\left[\mathrm{I}_{2}\right]$ is a very important factor for obtaining high monomer to polymer conversions. This ratio must be over 1.5 in order to allow the reaction to exit the inhibition period, due to AIBN being associated with an efficiency below unity. With a ratio 


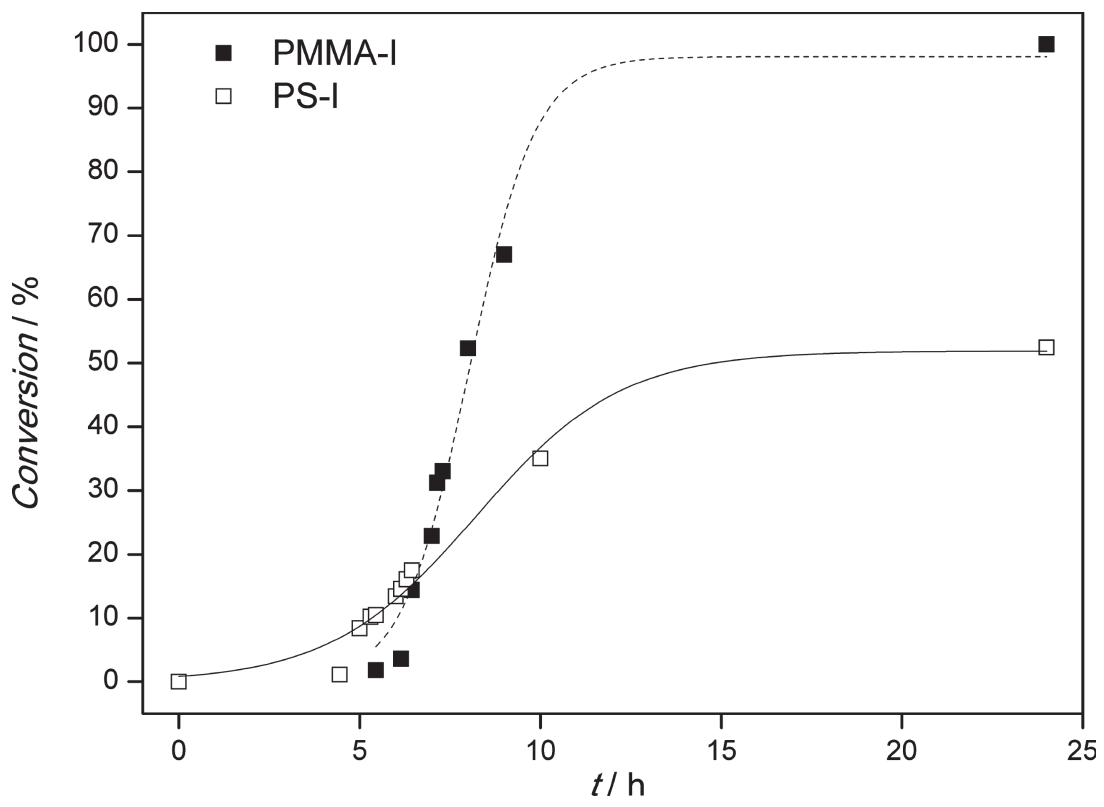

Figure 1. Conversion-time dependency for the reverse-iodine transfer radical polymerization of PMMA-I with $[\mathrm{MMA}] /[\mathrm{AIBN}] /\left[\mathrm{I}_{2}\right]=240 / 1.7 / 1$ at $75^{\circ} \mathrm{C}$ and for the reverse-iodine transfer radical polymerization of PS-I at with $[\mathrm{Sty}] /[\mathrm{AIBN}] /\left[\mathrm{I}_{2}\right]=180 / 1.8 / 1$ at $75^{\circ} \mathrm{C}$. The full and the dashed line are not fits and are only inserted as a reference to the followed trend.

under 1.5 the polymerization yield is very low and the reaction medium remains reddish. Due to these previous observations, we focused on an $[\mathrm{AIBN}] /\left[\mathrm{I}_{2}\right]$ ratio of over 1.7 for all experiments. The theoretical inhibition period varied slightly between the samples. The inhibition period can be calculated by Equation 2 with $\left[\mathrm{I}_{2}\right]_{0}$ being the initial concentration of iodine, $[\mathrm{AIBN}]_{0}$ is the initial concentration of initiator, $k_{\mathrm{d}}$ is the decomposition rate coefficient of the initiator $\left(k_{\mathrm{d}}=3.660 \times 10^{-5} \mathrm{~s}^{-1}\right.$ at $70^{\circ} \mathrm{C}, k_{\mathrm{d}}=7.133 \times 10^{-5} \mathrm{~s}^{-1}$ at $75^{\circ} \mathrm{C}, k_{\mathrm{d}}=1.331 \times 10^{-4} \mathrm{~s}^{-1}$ at $\left.80^{\circ} \mathrm{C}\right),{ }^{[50]}$ and $f$ is the initiator efficiency $(f=0.7$ for $\mathrm{AIBN}) .{ }^{[51,52]}$ This equation in general holds true for most acrylates and methacrylates.

$$
\text { time }_{\text {theoretical }}^{\text {inhibition }}=\frac{-\ln \left(1-\frac{\left[\mathrm{I}_{2}\right]_{\circ}}{f \times[\mathrm{AIBN}]_{\circ}}\right)}{k_{\mathrm{d}}}
$$

The targeted molecular weight adheres to the following relation:

$$
M_{\mathrm{n}, \text { targeted }}=[\mathrm{M}]_{0} \times \frac{M^{\mathrm{mon}} \cdot X}{2 \times\left[\mathrm{I}_{2}\right]_{0}}+M^{\mathrm{A}-\mathrm{I}}
$$

where $[M]_{0}$ is the initial concentration of monomer, $M^{\text {mon }}$ is the molecular weight of the monomer $\left(M^{\mathrm{MMA}}=\right.$ $100.12 \mathrm{~g} \mathrm{~mol}^{-1}$ and $\left.M^{S T Y}=104.15 \mathrm{~g} \mathrm{~mol}^{-1}\right), X$ is the conversion of monomer and $M^{\mathrm{A}-\mathrm{I}}$ is the molecular weight of the chain ends $\left(M^{\mathrm{A}-\mathrm{I}}=195.00 \mathrm{~g} \mathrm{~mol}^{-1}\right)$.

The RITP reactions of MMA with $[\mathrm{MMA}] /[\mathrm{AIBN}] /\left[\mathrm{I}_{2}\right]=$ 240/1.7/1 were carried out at $75{ }^{\circ} \mathrm{C}$ and monitored over time resulting in a linear increase of conversion versus reaction time. In Figure 1 the conversion-time profile is depicted and the inhibition period-ending around $6.5 \mathrm{~h}$-can be clearly observed, which agrees well with the theoretically expected value of $6.9 \mathrm{~h}$. A steady linear growth is observed thereafter as is generally in line with a radical polymerization (in fact a slight curvature may be expected due to the decrease in monomer concentration). At $9 \mathrm{~h}$, conversion has reached $\approx 70 \%$, after $24 \mathrm{~h}$, full conversion was observed.

A similar system was applied to the RITP of styrene with [Sty]/[AIBN]/[I $\left.\mathrm{I}_{2}\right]=$ 180/1.8/1 at $75{ }^{\circ} \mathrm{C}$, exhibiting an inhibition period of approximately $5 \mathrm{~h}$, as can also be observed from Figure 1 . In contrast to the MMA system, this time span does not correlate well with the theoretically calculated inhibition period of $5.7 \mathrm{~h}$. Such a reduction was, however, reported before and is in-line with previous research. ${ }^{[27,28]}$ Full conversion was not achieved in the $24 \mathrm{~h}$ period monitored.

Tonnar et al. ${ }^{[27]}$ and Shiman et al. ${ }^{[28]}$ noted earlier that RITP of styrene may follow a different mechanism compared to acrylates and methacrylates with experimental inhibition times that are typically shorter than theoretical inhibition times. It was the speculated that the shortened inhibition time can be attributed to the formation of 1,2-diiodoethylbenzene, which may deplete the concentration of free iodine. However, there has been no experimental evidence of this being formed during the inhibition period of RITP. In addition, at lower targeted molecular weights (that is, below $25000 \mathrm{~g} \mathrm{~mol}^{-1}$ ), it was observed that at conversions equal to or higher than $50 \%$ the reaction rate decreases significantly, as can also be seen in Figure 1. The origin of this effect remains unclear, to date, but could be due to the high viscosity of the reaction medium or the occurrence of irreversible chain termination. Regardless, while it is worthwhile to note that the results presented in Figure 1 are well in agreement with literature data, a full kinetic survey was not the scope of our investigations. Thus, no further studies were performed regarding the mechanism of styrene polymerization

\subsection{NMRC of Macro-transfer Agents PS-I (4) and PMMA-I (5)}

To perform NMRC reactions, both PS and PMMA with controlled molecular weight and good end-group functionality $(>90 \%)$ were required to be synthesized. Using a low

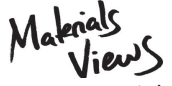

www.MaterialsViews.com 


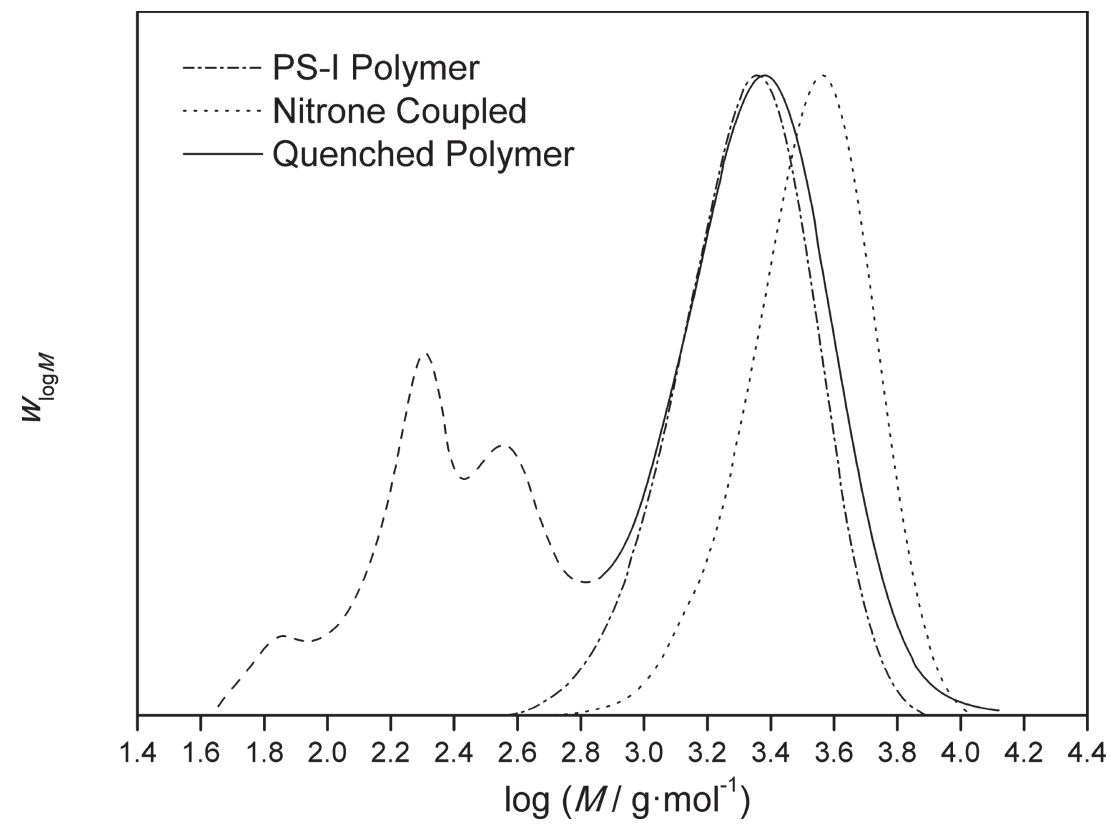

Figure 2. Molecular weight distributions of PS-I (4) before nitrone coupling, after NMRC (7) with 5 eq. PBN, 5 eq. $\mathrm{Cu}(0), 1$ eq. $\mathrm{Cu}(\mathrm{I}) \mathrm{Cl}$, and 10 eq. HMTETA as a ligand and after quenching of the alkoxyamine bond with TBTH.

monomer to initiator ratio ([Sty]/[AIBN $] /\left[\mathrm{I}_{2}\right]=48 / 1.7 / 1$ and $\left.[\mathrm{MMA}] /[\mathrm{AIBN}] /\left[\mathrm{I}_{2}\right]=60 / 1.7 / 1\right)$, the molecular weight was controlled even at high monomer conversions and good endgroup functionality was retained. The synthesis of a suitable PS-I (4) macro-transfer agent was performed at $70^{\circ} \mathrm{C}$ for $24 \mathrm{~h}$. The polymerization had reached $58 \%$ conversion at this stage, well in line with the experiments at $75{ }^{\circ} \mathrm{C}$ described above where likewise full conversions were never reached. The polymer reached a molecular weight of $1800 \mathrm{~g} \mathrm{~mol}^{-1}$ with a dispersity of close to 1.3 (see Figure 2). Using only $\mathrm{Cu}(0)$ did not result in a direct coupling of chains using NMRC. The use of a catalytic amount of $\mathrm{CuBr}$ or $\mathrm{CuCl}$ was necessary to push the reaction forward. $\mathrm{CuCl}$ was used due to more a favorable halide exchange mechanism occurring:

$$
\mathrm{RI}+\mathrm{CuCl} / 2 \mathrm{~L} \stackrel{\mathrm{K}_{\mathrm{eq}}^{\text {exch }}}{\rightleftharpoons} \mathrm{RCl}+\mathrm{CuI} / 2 \mathrm{~L}
$$

It was previously reported by Nottelet et al., ${ }^{[19]}$ it was reported that it was necessary to utilize such halide exchange to promote the reaction for a classical atom transfer radical coupling (ATRC). Moreover, Matyjaszwski et al. ${ }^{[53]}$ further reported that a mixed halogen system presents advantages over a traditional $\mathrm{R}-\mathrm{Br} / \mathrm{CuBr}$ system in the ATRP of MMA. In consequence, we applied the above strategy in our coupling reactions with both styrene and MMA. The major advantage observed in classical ATRP or ATRC was that initiation becomes faster while the propagation is slower resulting in a more controlled polymerization. When the more labile $\mathrm{C}-\mathrm{I}$ bond is being transformed into a more stable $\mathrm{C}-\mathrm{Cl}$ bond, the ATRP process in contrast, an efficiency of 0.99 was identified. Using other methods such as ATRC of bromine-end-capped PS resulted in efficiencies ranging from 0.2 to 0.97 using various conditions. ${ }^{[5,54,55]}$ For ATRC of PS-I, a value of 0.94 was previously reported by Nottelet et al. ${ }^{[19]}$ using similar reaction conditions without the addition of a nitrone. The somewhat lower efficiency found for PS-I in the present case might be associated with an imperfect endgroup fidelity or by a still partially hindered activation of the iodine end groups. Overall the reaction might still be considered successful, especially since the molecular weight distributions do not exhibit any visible shoulders.

To confirm that the coupling occurred via NMRC and not via the competing ATRC, the resulting macroalkoxyamine was quenched. As is seen in Figure 2, the quenched polymer distribution is almost equal to the starting PS-I distribution, demonstrating that indeed all of the coupling product was bridged with a thermally labile alkoxyamine rather than a stable $\mathrm{C}-\mathrm{C}$ bond, which would be formed upon classical ATRC. If average molecular

Table 1. Resulting molecular weights and polydispersities of polymers obtained in the coupling reaction of PS-I (4) using NMRC and after quenching of the alkoxyamine bond.

\begin{tabular}{lccc}
\hline & $\begin{array}{c}\boldsymbol{M}_{\mathbf{n}} \\
{\left[\mathbf{g ~ m o l}^{-\mathbf{1}}\right]}\end{array}$ & $\boldsymbol{Ð}$ & $\boldsymbol{x}_{\mathbf{c}}$ \\
\hline PS-I (4) precursor polymer & 1800 & 1.26 & \\
Coupled PS (7) & 2900 & 1.22 & 0.74 \\
Ouenched & 2100 & 1.30 &
\end{tabular}




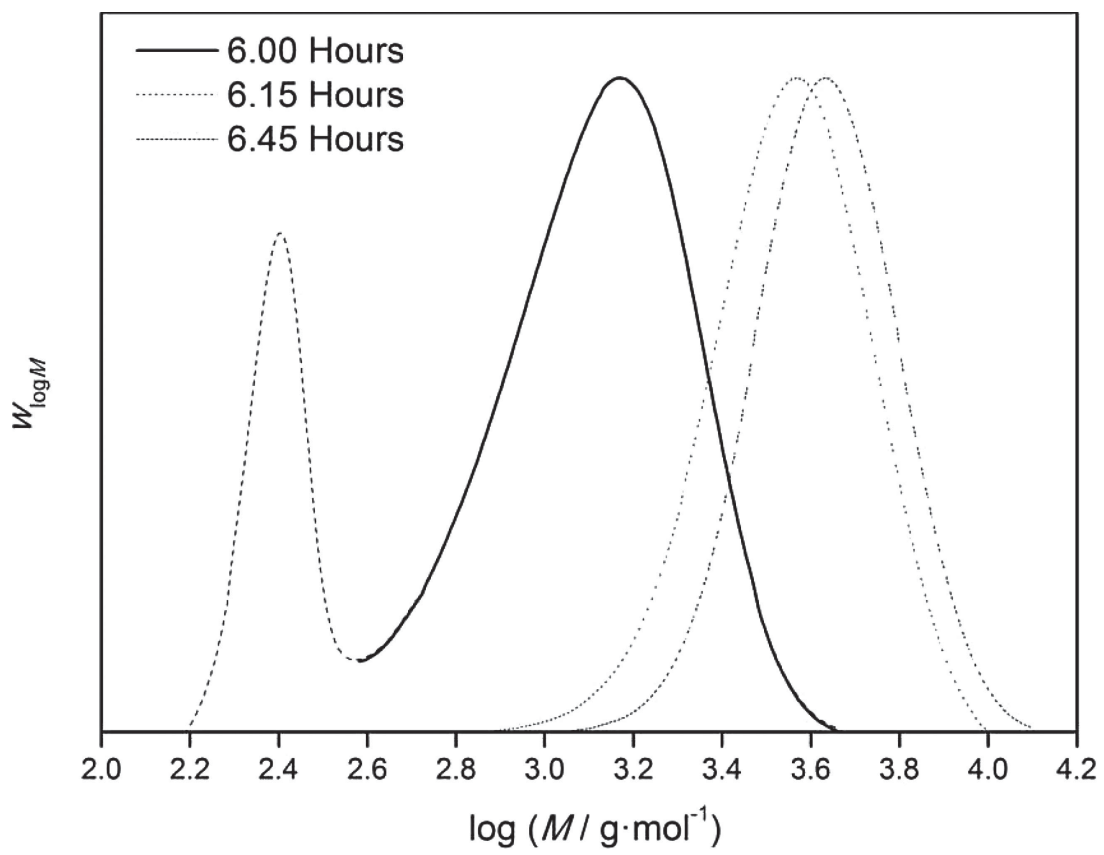

Figure 3. Molecular weight distributions of PMMA-I (5) after reaction times of 6.00, 6.15 , and $6.45 \mathrm{~h}$ in the reverse-iodine transfer polymerization with $[\mathrm{MMA}] /[\mathrm{AIBN}] /\left[\mathrm{I}_{2}\right]=$ $240 / 1.7 / 1$ at $80^{\circ} \mathrm{C}$.

weights are compared, a slight increase in $M_{\mathrm{n}}$ is seen after quenching when compared to the original starting material, due to small molecular weight material being present in the distribution stemming from the quenching process (reacted and residual quencher). This material was cut-off in the SEC analysis, but is for the sake of completeness depicted in Figure 2.

The synthesis of macro-transfer agent PMMA-I (5) for NMRC coupling was performed by RITP with reaction times between 6 and $7 \mathrm{~h}$ using identical conditions as discussed above. In all cases (Figure 3 and Table 2), a CRP can be observed and after approximately $7 \mathrm{~h}$ full conversion of monomer is reached, while retaining a satisfactory dispersity (1.15-1.25). With the samples depicted, it can readily be seen how fast the polymerization proceeds after the initialization phase. The small molecular weight peak seen in the sample taken at $6 \mathrm{~h}$, most likely results from residual monomer left-overs trapped in the polymer matrix.

To confirm the presence of iodine end-group functionalities, the low-molecular-weight PMMA-I of $1200 \mathrm{~g} \mathrm{~mol}^{-1}$ was subjected to ESI-MS analysis (see Figure 4 and Table 3). The overall spectrum reveals the repeating unit of $100.12 \mathrm{Da}$ as expected for PMMA as the major peak series. The other observed peaks correspond to single charged $\mathrm{K}^{+}$and double charged $\mathrm{Na}^{+}$species of the expected iodine-terminated product. This confirms the successful synthesis of a macro-transfer reagent PMMA-I (5) with practically $100 \%$ end-group functionality.
NMRC was applied to the PMMA-I sample taken after $6.15 \mathrm{~h}$ RITP reaction time. Previous attempts to perform NMRC of an ATRP produced PMMA failed. During ESCP of MMA, addition of styrene was necessary to activate the chains since the addition rate of PMMA macroradicals to PBN is too low. ${ }^{[40]}$ Additionally, PMMA macroradicals have a high probability to terminate via disproportionation, also with nitroxide species. Styrene is in that respect also beneficial since it promotes combination reactions. For the NMRC of the PMMA-I (5), different amounts of added styrene were tested and the optimumadded equivalents were found to be 10 in relation to PMMA-I. Using lower equivalents resulted in lower coupling efficiencies, higher amounts result in block copolymerizations. The halide exchange mechanism (Equation 4) described for the PS-I precursor was further utilized for PMMA-I, resulting (see Figure 5 and Table 4) in an increase of the average molecular weight from 3200 to $6600 \mathrm{~g} \mathrm{~mol}^{-1}$ and thus to more than doubling in molecular weight. This excess in size, while retaining good monomodality of the residual distributions, can be explained by addition of few styrene units to the MMA terminus and hence polymerization before the nitrone is added. In fact, the polymer formed in the coupling reaction has the structure of PMMA- $b$-PS- $b$-PMMA whereby the PS block is very short. It should be noted, however, that the PS addition is not controlled, and thus even at low monomer concentrations, significant chain growth may occur. The integrity of the coupling product is, however, not compromised by the presence of an uncontrolled polymerization. Modeling of very similar reactions for triblock copolymer formations in radical coupling of cobalt-mediated polymerization products demonstrated that the coupling mechanism dominates over the uncontrolled reaction and that conventional termination does not need to be taken into

Table 2. Resulting molecular weights and dispersities of polymers obtained after various reaction times for reverse-iodine transfer polymerization of PMMA (5) with $M_{n \text {,targeted }}=3200 \mathrm{~g} \mathrm{~mol}^{-1}$.

\begin{tabular}{lcc}
\hline $\begin{array}{l}\text { Time } \\
\text { [h] }\end{array}$ & $\begin{array}{c}\boldsymbol{M}_{\mathbf{n}} \\
{\left[\mathrm{g} \mathrm{mol}^{-1}\right]}\end{array}$ & $\boldsymbol{Ð}$ \\
\hline 6.00 & 1200 & 1.25 \\
6.15 & 3300 & 1.18 \\
6.45 & 4000 & 1.15 \\
& & \\
014, 215, 1991-2000 & &
\end{tabular}



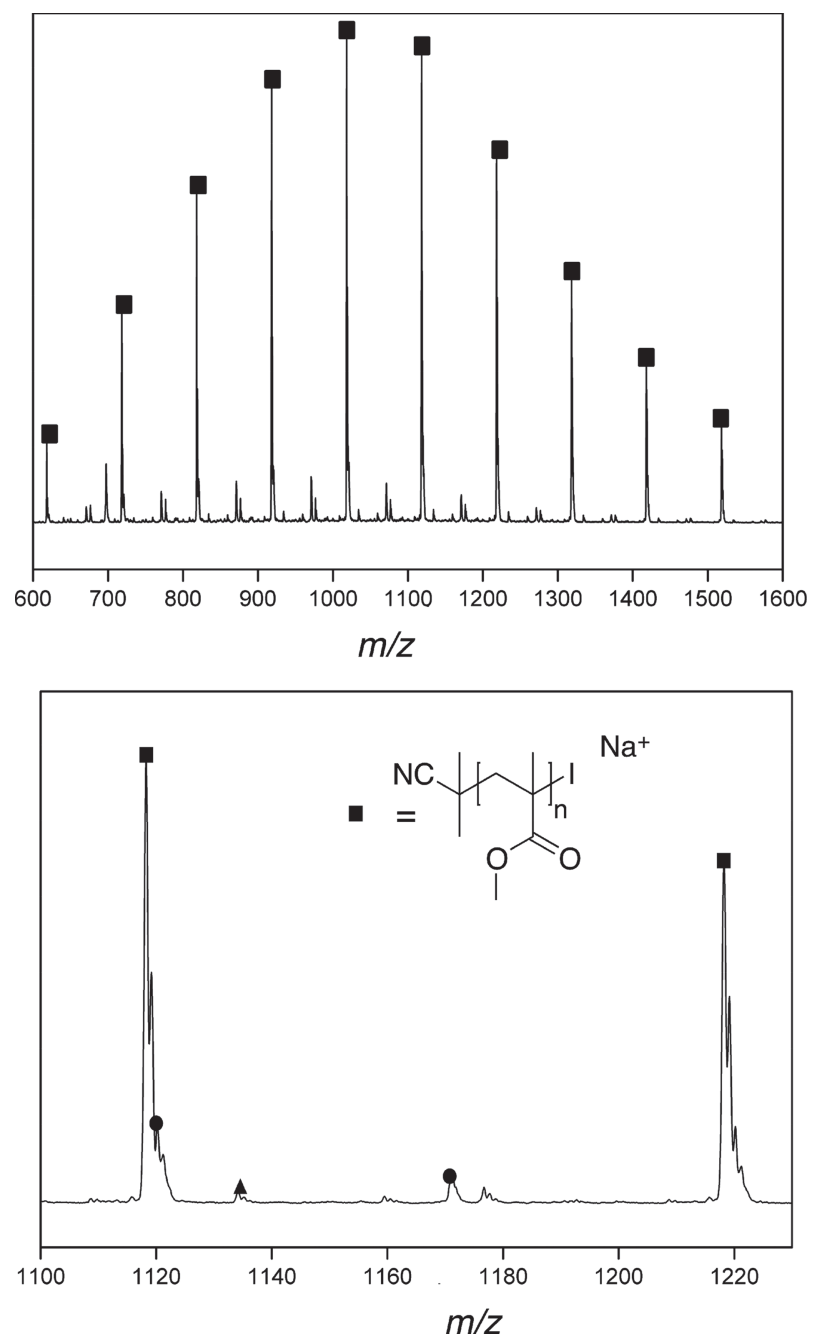

Figure 4. ESI-MS spectrum of the low-molecular-weight PMMA-I (5) obtained after $6 \mathrm{~h}$ reaction time.

account. ${ }^{[56]}$ To determine the quantity of styrene units incorporated into the chain, alkoxyamine quenching was performed. Again, using high temperatures and a radical scavenger the alkoxyamine bond can be cleaved. Ideally, the original PMMA-I (5) distribution should be retained. However, due to the styrene addition, larger molecular weights must be expected. From this difference, an addition of roughly 13 styrene units per PMMA chain can be

Table 3. Experimental and theoretical $m / z$ for products identified in the mass spectra of low-molecular-weight PMMA-I (5).

\begin{tabular}{lcccc}
\hline Symbol & Species & $\begin{array}{c}m / z_{\text {theo }} \\
{[\mathrm{Da}]}\end{array}$ & $\begin{array}{c}\boldsymbol{m} / \mathbf{z}_{\text {exp }} \\
{[\mathrm{Da}]}\end{array}$ & $\begin{array}{c}\Delta \boldsymbol{m} / \mathbf{z} \\
{[\mathrm{Da}]}\end{array}$ \\
\hline Square & $\mathrm{NC}-\mathrm{t}-[\mathrm{M}]_{9}-\mathrm{I} ; \mathrm{Na}^{+}$ & 1118.42 & 1118.25 & 0.17 \\
Circle & $\mathrm{NC}-\mathrm{t}-[\mathrm{M}]_{21}-\mathrm{I} ; 2 \mathrm{Na}^{+}$ & 1171.01 & 1171.33 & 0.32 \\
Triangle & $\mathrm{NC}-\mathrm{t}-[\mathrm{M}]_{9}-\mathrm{I} ; \mathrm{K}^{+}$ & 1134.39 & 1134.17 & 0.22
\end{tabular}

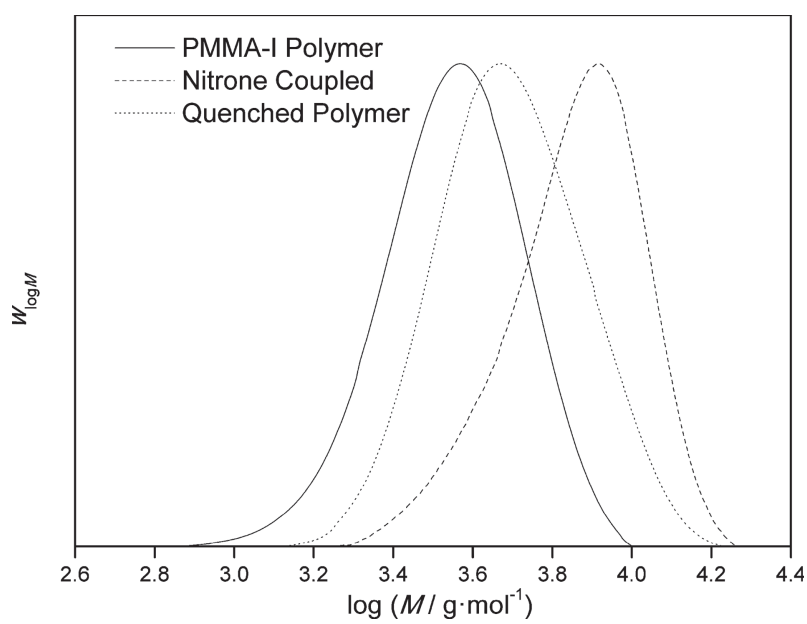

Figure 5. Molecular weight distribution of PMMA before nitrone coupling (5), after NMRC (6) with 10 eq. styrene, 5 eq. PBN, 5 eq. $\mathrm{Cu}(0), 1$ eq. $\mathrm{Cu}(\mathrm{I}) \mathrm{Cl}$, and 10 eq. PMDETA as a ligand and after quenching of the alkoxyamine bond with TBTH.

calculated. Assuming that indeed an average of 13 units of styrene is built into the chain before nitrone addition, forming a macronitroxide that will then react with a PMMA macroradical, a coupling efficiency of about 0.84 is calculated, a number that is well in line with the observed values for PS-I (7).

\section{Conclusion}

A series of iodine-capped polymers was synthesized using RITP and selected samples were further subjected to NMRC reactions. To obtain well-defined precursor polymers for the coupling reaction, the RITP of both MMA and styrene was studied in detail to identify optimal reaction times for reaching the desired molecular weights. PS-I was successfully subjected to NMRC resulting in good incorporation of the nitrone into the polymer structure. A coupling efficiency of $x_{\mathrm{c}}=0.74$ was obtained. In addition to the radical coupling agents, $\mathrm{CuCl}$ was required to promote the reaction to simultaneously perform a halide exchange reaction

Table 4. Resulting molecular weights and dispersities of polymer obtained in coupling reactions of PMMA-I (5) polymer using NMRC and after quenching of the alkoxyamine bond.

\begin{tabular}{lccc}
\hline & $\begin{array}{c}\overline{\mathbf{M}}_{\mathrm{n}} \\
{\left[\mathrm{g} \mathrm{mol}^{-\mathbf{1}}\right]}\end{array}$ & $\boldsymbol{\Xi}$ & $\boldsymbol{x}_{\mathrm{c}}$ \\
\hline PMMA-I (5) precursor polymer & 3200 & 1.17 & \\
Nitrone-coupled PMMA (6) & 6600 & 1.16 & 0.84 \\
Quenched & 4500 & 1.18 &
\end{tabular}


since iodine is not sufficiently reactive to directly undergo chain coupling. PMMA-I cannot be successfully coupled using NMRC if no additive is employed since MMA radical termini do not add to nitrones at a sufficient rate. Satisfactory results for the NMRC could, however, be obtained when 10 equivalents of styrene were added to the reaction mixture. Approximately, all styrene is built into the coupled polymer chains, thus resulting in coupled polymers of a PMMA- $b$-PS- $b$-PMMA structure. Successful incorporation of the nitrone is demonstrated by the ability to quench the coupling products, also revealing a coupling efficiency of roughly 0.84 .

\section{Supporting Information}

Supporting Information is available from the Wiley Online Library or from the author.

Acknowledgements: C.B.-K. acknowledges continued support from the Karlsruhe Institute of Technology (KIT) and the Helmholtz association in the context of the Biointerfaces and STN programs. K.R., J.V., and T.J. are grateful for the funding from the Fonds Wetenschappelijk Onderzoek (FWO) via project G.0491.11N and the Odysseus scheme.

Received: November 26, 2013; Published online: February 20, 2014; DOI: 10.1002/macp.201300740

Keywords: kinetics(polym); reverse-iodine transfer polymerization; radical coupling; spin trapping

[1] R. J. Ceresa, Block and Graft Copolymers, Vol. 1, Wiley, New York 1973.

[2] M. K. Mishra, Macromolecular Engineering, Plenum Press, New York 1995.

[3] B. Ameduri, B. Boutevin, P. Gramain, Adv. Polym. Sci. 1997, $127,87$.

[4] K. A. Davis, K. Matyjaszewski, Adv. Polym. Sci. 2002, 159, 2.

[5] K. Matyjaszewski, J. Xia, Chem. Rev. 2001, 101, 2921.

[6] J. S. Wang, K. Matyjaszewski, J. Am. Chem. Soc. 1995, 117, 5614.

[7] M. Kato, M. Kamigaito, M. Sawamoto, T. Higashimura, Macromolecules 1995, 28, 1721.

[8] M. Kamigaito, T. Ando, M. Sawamoto, Chem. Rev. 2001, 101, 3689.

[9] C. J. Hawker, A. W. Bosman, E. Harth, Chem. Rev. 2001, 301, 3661.

[10] J. Nicolas, Y. Guillaneuf, C. Lefay, D. Bertin, D. Gigmes, B. Charleux, Prog. Polym. Sci. 2013, 38, 63.

[11] J. Chiefari, Y. K. Chong, F. Ercole, J. Krstina, J. Jeffery, T. P.T. Le, R. T.A. Mayadunne, G. F. Meijs, G. Moad, E. Rizzardo, S. H. Thang, Macromolecules 1998, 31, 5559.

[12] G. Moad, C. Barner-Kowollik, in Handbook of RAFT Polymerization, (Ed: C. Barner-Kowollik), Wiley-VCH, Weinheim, Germany 2008.

[13] M. Tatemoto, M. Tomoda, Y. Ueta, (Daikin), German Patent DE 2940135, 1980.

[14] M. Tatemoto, Y. Yutani, K. Fujiwara, (Daikin Industries, Ltd. Japan), Eur. Pat. Appl. 550288, 1988
[15] Y. Yutani, M. Tatemoto, (Daikin Industries, Ltd. Japan), Eur. Pat. Appl. 0489370, 1992.

[16] Y. Yutani, M. Tatemoto, (Daikin Industries, Japan), US Patent 5439980, 1995.

[17] K. Matyjaszewski, S. Gaynor, J. S. Wang, Macromolecules 1995, 28, 2093.

[18] S. Gaynor, J. S. Wang, Macromolecules 1995, 28, 8051.

[19] B. Nottelet, P. Lacroix-Desmazes, B. Boutevin, Polymer 2007, $48,50$.

[20] C. Boyer, P. Lacroix-Desmazes, J.-J. Robin, B. Boutevin, Macromolecules 2006, 39, 4044

[21] N. Greesh, R. Sanderson, P. Hartmann, J. Appl. Polym. Sci. 2012, 126, 1773

[22] P. Lacroix-Desmazes, R. Severac, B. Boutevin, Macromolecules 2005, 38, 6299.

[23] P. Lacroix-Desmazes, R. Severac, B. Otazaghine, B. Boutevin, Polym. Prepr. (Am. Chem. Soc. Div. Polym. Chem.) 2003, 44, 683.

[24] J. Tonnar, P. Lacroix-Desmazes, B. Boutevin, Polym. Prepr. (Am. Chem. Soc. Div. Polym. Chem.) 2005, 46, 280.

[25] J. Tonnar, P. Lacroix-Desmazes, B. Boutevin, ACS Symp. Ser. 2006, 944, 604

[26] J. Tonnar, P. Lacroix-Desmazes, B. Boutevin, Macromolecules 2007, 40, 6076

[27] J. Tonnar, R. Severac, P. Lacroix-Desmazes, B. Boutevin, Polym. Prepr. (Am. Chem. Soc. Div. Polym. Chem.) 2008, 49, 68

[28] D. I. Shiman, S. V. Kostyuk, L. V. Gaponik, F. N. Kaputskii, Russ. J. Appl. Chem. 2010, 83, 2028.

[29] E. H. H. Wong, T. Junkers, C. Barner-Kowollik, Polym. Chem. 2011, 2, 1008.

[30] E. H. H. Wong, C. Boyer, M. H. Stenzel, C. Barner-Kowollik, T. Junkers, Chem. Commun. 2010, 46, 1959.

[31] A. Debuigne, M. Hurtgen, C. Detrembleur, C. Jérôme, C. Barner-Kowollik, T. Junkers, Prog. Polym. Sci. 2012, 37, 1004.

[32] E. H. H. Wong, T. Junkers, C. Barner-Kowollik, J. Polym. Sci., Part A: Polym. Chem. 2008, 46, 7273.

[33] E. H. H. Wong, M. H. Stenzel, T. Junkers, C. Barner-Kowollik, Macromolecules 2010, 43, 3785.

[34] K. Ranieri, M. Conradi, P.-Y. Chavant, V. Blandin, C. BarnerKowollik, T. Junkers, Aust. J. Chem. 2012, 65, 1110.

[35] C. Detrembleur, A. Debuigne, O. Altintas, M. Conradi, E. H. H. Wong, C. Jérôme, C. Barner-Kowollik, T. Junkers, Polym. Chem. 2012, 3, 135.

[36] T. Junkers, L. Zang, E. H. H. Wong, N. Dingenouts, C. Barner-Kowollik, J. Polym. Sci., Part A: Polym. Chem. 2011, 49, 4841.

[37] O. Fu, Z. Zhang, W. Lin, J. Huang, Macromolecules 2009, 42 4381.

[38] E. H. H. Wong, T. Junkers, C. Barner-Kowollik, J. Polym. Sci., Part A: Polym. Chem. 2008, 46, 7273.

[39] E. H. H. Wong, M. H. Stenzel, T. Junkers, C. Barner-Kowollik, J. Polym. Sci., Part A: Polym. Chem. 2009, 47, 1098.

[40] L. Zang, E. H. H. Wong, C. Barner-Kowollik, T. Junkers, Polymer 2010, 51, 3821.

[41] T. Junkers, E. H. H. Wong, M. H. Stenzel, C. Barner-Kowollik, Macromolecules 2009, 42, 5027.

[42] C. Dommanget, C. Boisson, B. Charleux, F. D'Aosto, V. Monteil, F. Boisson, T. Junkers, C. Barner-Kowollik, Y. Guillaneuf, D. Gigmes, Macromolecules 2013, 46, 29.

[43] J. Nicolas, C. Dire, L. Mueller, J. Belleney, B. Charleux S. R. A. Marque, D. Bertin, S. Magnet, L. Coureur, Macromolecules 2006, 39, 8274

[44] J. Nicolas, L. Mueller, C. Dire, K. Matyjaszewski, B. Charleux Macromolecules 2009, 42, 4470.

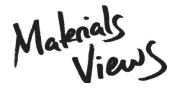

www.MaterialsViews.com 
[45] J. Nicolas, S. Brusseau, B. Charleux, J. Polym. Sci., Part A: Polym. Chem. 2010, 48, 34.

[46] C. Strazielle, H. Benoit, O. Vogl, Eur. Polym. J. 1978, 14, 331.

[47] E. Penzel, N. Goetz, Angew. Makromol. Chem. 1990, 178, 191.

[48] S. Beuermann, M. Buback, T. P. Davis, R. G. Gilbert, R. A. Hutchinson, A. Kajiwara, B. Klumperman, G. T. Russell, Macromol. Chem. Phys. 2000, 201, 1355.

[49] T. Sarbu, K.-Y. Lin, J. Ell, D. J. Siegwart, J. Spanswick, K. Matyjaszewski, Macromolecules 2004, 37, 3120.
[50] J. P. Van Hook, A. B. Tobolsky, J. Am. Chem. Soc. 1958, 80, 779.

[51] C. E. Brawn, D. Verdon, Trans. Faraday Soc. 1960, 56, 812.

[52] G. Moad, E. Rizzardo, D. H. J. Solomon, R. I. Willing, Makromol. Chem. Rapid Commun. 1984, 5, 793.

[53] K. Matyjaszewski, D. A. Shipp, J.-L. Wang, T. Grimaud, T. E. Patten, Macromolecules 1998, 31, 6836.

[54] C. Yoshokawa, A. Goto, T. Fukuda, e-Polymers 2002, 13, 1.

[55] B. Otazaghine, G. David, B. Boutevin, J. J. Robin, K. Matyjaszewski, Macromol. Chem. Phys. 2004, 205, 154.

[56] A. Debuigne, C. Jérôme, C. Detrembleur, T. Junkers, Macromolecules 2013, 46, 8922 